\title{
Ropivacaine, Articaine or Combination of Ropivacaine and Articaine for Epidural Anesthesia in Cesarean Section: a Randomized, Prospective, Double-Blinded Study
}

Derya Arslan Yurtlu* ${ }^{*}$, Kadir Kaya ${ }^{2}$

1. MD; Zonguldak Ataturk State Hospital, Department of Anesthesiology and Reanimation, Ankara, Turkey

2. MD; Prof. Dr, Gazi University Faculty of Medicine, Anesthesiology and Reanimation Department, Ankara, Turkey Received from Gazi University Faculty of Medicine, Anesthesiology and Reanimation Department, Ankara, Turkey. A part of this work has been presented at Turkish Anesthesia and Reanimation Congress, Antalya, 2008.

Submitted on February 6, 2012. Approved on March 15, 2012.

\section{Keywords:}

Anesthesia, Epidural;

Anesthetics,

Local/ropivacaine;

Carticaine;

Cesarean Section.

\begin{abstract}
Background and objectives: Initiation of epidural anesthesia with long-lasting local anesthetics consumes a significant amount of time, which could be problematic in busy obstetric anesthesia suites. We have hypothesized that a combination of articaine and ropivacaine provides faster onset and even an early recovery of sensory-motor block characteristics.

Methods: Sixty term parturients scheduled to have elective cesarean section were randomly allocated into three groups to receive either $20 \mathrm{~mL}$ 2\% articaine (Group A), $10 \mathrm{~mL}$ 2\% articaine $+10 \mathrm{~mL} 0.75 \%$ ropivacaine (Group AR) or $20 \mathrm{~mL} 0.75 \%$ ropivacaine (Group R) via lumbar epidural catheter. The onset time of sensory block to $T_{10} T_{6}$ and maximum sensory block level, time to two segments regression from maximum sensory block level, onset time and duration of motor block were all recorded. Intraoperative and postoperative additional analgesic requirements were also recorded.

Results: Demographic data were similar. The onset times of sensorial block to $T_{10}$ and $T_{6}$ were significantly shorter in Groups A and AR in comparison with Group R $(p<0.05)$. The onset times of motor block were similar in all groups, but a more intense motor block was observed in Group $R$ $(p<0.05)$. Two segments regression time and motor block durations were significantly shorter in Groups A and AR in comparison with Group R ( $<0.05)$. Intraoperative supplementary analgesic requirements were higher in Group $A$ than in the other two groups $(p<0.05)$.

Conclusion: A combination of $2 \%$ articaine and $0.75 \%$ ropivacaine for epidural anesthesia in a cesarean section should be preferred over epidural $0.75 \%$ ropivacaine alone.

(c) 2013 Sociedade Brasileira de Anestesiologia. Published by Elsevier Editora Ltda. All rights reserved.
\end{abstract}

* Corresponding author: Zonguldak Ataturk State Hospital, Department of Anesthesiology and Reanimation

E-mail: dayurtlu@gmail.com 


\section{Introduction}

Epidural anesthesia allows the adjustment of intraoperative sensory block level with a catheter and offers postoperative analgesia ${ }^{1,2}$. However, the time needed for the provision of adequate sensory block in epidural anesthesia constitutes a problem for busy obstetric anesthesia operation theatres ${ }^{1-3}$. This is especially important when long-lasting local anesthetics are used for epidural anesthesia.

None of the local anesthetics in current practice carry properties such as fast onset of action, long sensory block duration and short motor block duration to enable early mobilization after epidural anesthesia. In order to avail these properties, adjuvants have been used with local anesthetics ${ }^{4-9}$ or local anesthetics with different properties have been combined ${ }^{10}$. Ropivacaine, due to its weaker motor block effect, has become popular for obstetric anesthesia and analgesia in the last two decades. However, ropivacaine provides a similar speed of sensory block onset as bupivacaine but does not provide faster onset for epidural anesthesia ${ }^{11-13}$. An amide group local anesthetic, articaine, has a fast onset and offset time due to its high lipid solubility ${ }^{14,15}$. Articaine has a short sensory and motor block onset of action and low toxicity profile; its use had been described for epidural anesthesia ${ }^{15-18}$. The use of combinations of different local anesthetics for epidural anesthesia in cesarean surgeries has been studied in the literature ${ }^{9,10}$, however we did not come across any study that combines articaine and ropivacaine for epidural anesthesia.

We have hypothesized that a combination of articaine and ropivacaine for epidural anesthesia of cesarean sections could provide faster onset and yet longer postoperative analgesia with minimal motor blockade. The primary outcome was sensory block onset time. Thus, we compared the sensory and motor block characteristics of epidural anesthesia with the use of ropivacaine and articaine, in equal amounts, separately and combined for patients selected for cesarean section.

\section{Methods}

Prior to the study, the chromatograms of $0.75 \%$ ropivacaine and $2 \%$ articaine were analyzed both separately and in a solution of both mixed in equal volumes by using a Gas Chromatography/Mass Spectrometry device (GC/MS; Agilent 6890 GS System 5973 MDS, Germany) ${ }^{19}$ (Figure 1). The pH of the local anesthetics alone and mixed solutions were determined.

After obtaining hospital ethics board approval and written informed consents from patients, 60 pregnant women over the age of 18 from the ASA I-II risk group who were scheduled for elective cesarean surgery were included in the study. Exclusion criteria included: history of preeclampsia, psychiatric disorders and allergies to amid type local anesthetics, as well as pregnancy terms other than 36-40 weeks, multiple pregnancies, and other contra-indications for epidural anesthesia. All patients in the study were introduced to the Patient Controlled Analgesia (PCA) device and informed on how to use it.

Patients were randomly distributed by a computer into three groups consisting of 20 patients each. The following procedures were planned for each group:

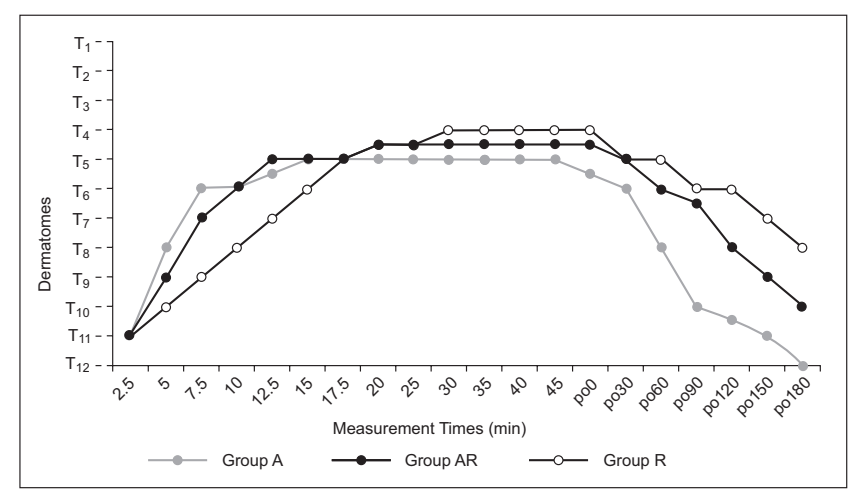

Figure 1 Cranial Spread of Sensory Block Levels within the Groups (Median).

Group A: $20 \mathrm{~mL} 2 \%$ articaine $+1 \mathrm{~mL}$ fentanyl (50 $\mu \mathrm{g})$

Group AR: $10 \mathrm{~mL} 0.75 \%$ ropivacaine $+10 \mathrm{~mL} 2 \%$ articaine $+1 \mathrm{~mL}$ fentanyl $(50 \mu \mathrm{g})$

Group R: $20 \mathrm{~mL} 0.75 \%$ ropivacaine $+1 \mathrm{~mL}$ fentanyl $(50 \mu \mathrm{g})$

\section{Anesthetic Procedures}

Premedication was not administered to any patient. They were admitted to the operation theatre after gaining vascular access and being administered $10 \mathrm{~mL}^{\mathrm{kg}} \mathrm{kg}^{-1} 0.9 \% \mathrm{NaCl}$ intravenous (iv) infusion in 15 minutes. Following this, the same fluid was used as maintenance infusion at $5 \mathrm{~mL} \cdot \mathrm{kg}^{-1} \cdot \mathrm{hr}^{-1}$. Each patient on the operating table was monitored by non-invasive methods, and the following parameters were recorded as a baseline value for hemodynamic measurements: mean arterial blood pressure (MBP), heart rate (HR), and peripheral $\mathrm{O}_{2}$ saturation $\left(\mathrm{SpO}_{2}\right)$ (Odam Physiogards SM 785, France). Epidural catheter was inserted at the better interspace of $\mathrm{L}_{2-3}$ or $\mathrm{L}_{3-4}$ when in a sitting position; then, the patients laid down on the operation table. The operation table was rotated $15^{\circ}$ to the left and all patients were given $3 \mathrm{~L} \cdot \mathrm{min}^{-1} \mathrm{O}_{2}$ by nasal catheter. A nurse anesthetist prepared the local anesthetic solution (Ultracain, Sanofi Aventis, Turkey; Naropin, AstraZeneca, Turkey) according to randomization. All patients received a $3 \mathrm{~mL}$ test dose of the prepared local anesthetic initially, then $50 \mu \mathrm{g}$ fentanyl and $17 \mathrm{~mL}$ of the same local anesthetic solution epidurally. The patients, as well as the anesthesiologist administering the drug and evaluating the block characteristics were unaware of the group allocations.

When sensory block did not reach $\mathrm{T}_{6} 20$ minutes after the injection of local anesthetic, $2 \mathrm{~mL}$ medication used in the study group was administered every 3 minutes, until block level reached $\mathrm{T}_{6}$. The operation was initiated when sensory block reached the $\mathrm{T}_{6}$ dermatome. In cases of insufficient analgesia - despite sensory block having reached the $T_{6}$ dermatome - the plan was for the patient to be evaluated by using the Visual Analog Scale (VAS; 0: no pain, 10: worst pain imaginable), and any VAS $\geq 3$ patient would be administered iv fentanyl $(50 \mu \mathrm{g})$. If not sufficient, they received a bolus dose of iv ketamine $(10 \mathrm{mg})$. There was a plan for general anesthesia in case the pain could not be controlled by additional iv analgesic. 
Cases where MBP decreased by $20 \%$ as compared to baseline values were treated with rapid fluid replacement and $5 \mathrm{mg}$ of ephedrine in bolus doses. When HR decreased below 50 beats. $\mathrm{min}^{-1}$, administration of $0.5 \mathrm{mg}$ iv atropine was planned. In cases of nausea, $10 \mathrm{mg}$ iv metoclopramide was planned. We took note of all drug applications and doses.

\section{Block evaluations}

We identified the dermatomal spread of sensory block in the cranial direction with a 25-Gauge needle "pin prick" test on the bilateral midclavicular line. We identified $\mathrm{SpO}_{2}$ with hemodynamic parameters every 2.5 minutes during the first 20 minutes after local anesthetic injection and every 5 minutes thereafter until the end of surgery; in the postoperative stage, every 30 minutes until minute 180 . Motor block levels were recorded by using Modified Bromage Scale (MBS) $(0=$ No block, $1=$ Difficulty lifting leg, $2=$ Difficulty with flexion at knee joint, $3=$ Difficulty with flexion at ankle) every 2.5 minutes for the first 17.5 minutes after epidural local anesthetic injection and every 30 minutes until minute 180 in the postoperative stage.

We took note of the following: times needed for sensory block to reach $\mathrm{T}_{10}, \mathrm{~T}_{6}$ and maximum levels, for regression from maximum sensory block by two dermatomes, and for sensory block to regress to the $T_{10}$ dermatome. Motor block onset time was defined and noted as the time between epidural injection to MBS 1 , and total motor block duration was defined and noted as the time between motor block onset to MBS 0 .

During the operation, the upper level of sensory block was assessed with the pinprick test during skin incision, the head of the baby being born, exposition of the uterus, closure of the peritoneum and skin suturing, and level of pain was assessed with VAS. Minutes 1 and 5 Apgar scores of the newborns were recorded.

After the operation, patients and surgeons evaluated the efficiency of epidural anesthesia as poor, moderate, good, or very good.

\section{Postoperative follow-up}

When the sensory block has regressed two dermatomes from its maximum level, $3 \mathrm{mg}$ morphine in saline was administered through the epidural catheter. Additionally, all patients were given a Patient Controlled Analgesia Device (Abbott, Pain Management Provider, USA) and a standard analgesia protocol ( $2 \mathrm{mg} \cdot \mathrm{mL}^{-1}$ ropivacaine and $2 \mu \mathrm{g} \cdot \mathrm{mL}^{-1}$ fentanyl; $6 \mathrm{~mL}$ bolus, $15 \mathrm{~min}$ lock-out time) for rescue analgesia. If additional analgesia was needed despite the PCA device we administered $20 \mathrm{mg}$ tenoxicam (Tilcotil $\circledast$, Roche, Sweden) every 12 hours.

We recorded the time of the first mobilization and passage of bowel gas in the postoperative stage. The data of PCA device and the need for additional analgesia were also noted in the protocol.

\section{Side effects}

We also noted possible side effects (nausea, vomiting, shivering) in the parturients during the perioperative stage.

\section{Sample size calculation}

We put forth the hypothesis that a combination of articaine and ropivacaine would produce a faster sensory block onset time for epidural anesthesia of cesarean sections in comparison with ropivacaine alone. The primary endpoint was the onset time of sensory block to T10. Sample size estimation was based on the similar study performed by Arslan et al. ${ }^{20}$.

In order to detect a $25 \%$ change in the onset time of sensory block ( $8.7 \pm 2.05$ minutes in the previous study), with a error of 0.05 and a power of $90 \%$, we calculated that sample size should be at least 19 patients per group. Twenty patients were enrolled in the groups. The sample size estimation was performed using Power Calculator ${ }^{21}$.

\section{Statistical analysis}

Statistical analysis was performed by using the Statistical Package for the Social Sciences (SPSS) version 16.0 for Windows (SPSS Inc., Chicago, IL, USA). Descriptive statistics included median and interquartile range (IQR) (\%25-\%75) for the numerical data, numbers and percentages for categorical data. Kolmogorov-Smirnov test was used to examine compatibility between measured variables and normal distribution. Mann-Whitney $U$ test was used to compare the averages of data with continuous measures such as: age, height, weight, gestational age, time needed for sensory block to reach $\mathrm{T}_{6}$, $\mathrm{T}_{10}$, motor block duration and first ephedrine time values. The Wilcoxon Signed Ranks Test was used to compare intragroup repeated measures, and the $x 2$ test was used to compare data that denotes frequency, such as gender and ASA risk category. A p value $<0.05$ (after Bonferroni correction, $p<0.0166$ ) was considered of statistical significance.

\section{Results}

The chromatograms revealed that $2 \%$ articaine and $0.75 \%$ ropivacaine did not react with each other and the amounts of each drug in the mixture did not change. The $\mathrm{pH}$ of $2 \%$ articaine was 4.16 , that of $0.75 \%$ ropivacaine was 5.06 , and that of the solution made by mixing equal volumes of articaine and ropivacaine was 4.39 .

There was no significant difference between the demographic data, pregnancy terms and surgical durations of the groups $(p>0.0166)$ (Table 1$)$.

\section{Block characteristics}

While the time needed for sensory block to reach $T_{10}$ and $T_{6}$ dermatomes and the maximum level were similar in Groups A and AR, these durations were shorter than Group R ( $<0.05)$. Maximum block levels were similar across groups; however, the time needed for regressing from the maximum block by two dermatomes and the time needed for sensory block to regress to $T_{10}$ in Group AR were longer than Group A and shorter than Group R ( $<$ 0.05) (Table 2).

The levels of sensory block in the cranial direction were higher in Groups A and AR than Group R at minutes 5, 7.5, $10,12.5$ and $15(p<0.05)$ (Figure 1$)$. 
Intraoperative sensory block levels in Group A were lower than Group R during the birth of the baby's head, exposition of the uterus and closure of the peritoneum, and lower than Groups AR and R during skin suturing $(p<0.05)$ (Figure 1).

Motor block onset was similar between the groups. Total motor block durations were shorter in Group A as compared to Groups AR and R, and in Group AR as compared to Group R $(p<0.05)$. Longer lasting and more dense motor block, according to MBS, was observed in Group R ( $<$ 0.05) (Table 2).

Total intraoperative fentanyl and ketamine usage were higher in Group A in comparison with Groups AR and $R$ $(p<0.05)$. There was no statistical significance between Groups AR and R in terms of total fentanyl and ketamine need. (Table 3 ). None of the patients required a shift to general anesthesia for inadequate sensory block.

Mean total local anesthetic volumes used in order to obtain adequate sensory block level to start surgery was $22.6 \pm 1.8 \mathrm{~mL}$ in Group A, $21.7 \pm 1.2 \mathrm{~mL}$ in Group AR, and $22.3 \pm 1.8 \mathrm{~mL}$ in Group R $(p>0.05)$.

\section{Hemodynamic data}

A comparison of hemodynamics showed that the MBP in groups were as follow: MBP in Groups $A$ and $A R$ was lower than Group R at minute 5, and, in Group A, it was higher than Group R at minute 15 ( $p>0.05)$. In the postoperative stage, MBPs remained higher in Group $A$ than in Groups AR and $R$ $(p<0.05)$. Comparisons within groups showed that all measurements in Group A at minutes 5, 7.5, 10 and 12.5, Group AR at minutes 5, 7.5, 10, 12.5, 15 and 25, and Group R at minute 7.5 through the end of the operation were statistically lower than the control value $(p<0.05)$. While a significant difference was not detected among the groups with respect to $H R$, the $H R$ value within Group $R$ remained higher than control values from minute 17.5 onwards $(p<0.05)$. In our study, bradycardia was observed in three patients $(15 \%)$ in both articaine and ropivacaine groups and in four patients (20\%) in the combined articaine and ropivacaine group. It was treated by administering $0.5 \mathrm{mg}$ atropine iv bolus. First intraoperative ephedrine administration times were compared between groups and Group A was found to have earlier administration times than Group R ( $<0.05)$, while

Table 1 Demographic Data, and Surgical Durations According to the Groups (Median, IQR).

\begin{tabular}{llll}
\hline & Group A $(\mathrm{n}=20)$ & Group AR $(\mathrm{n}=20)$ & Group R $(\mathrm{n}=20)$ \\
\hline Age $($ year) & $34(26.2-34.7)$ & $29(26.2-33.0)$ & $29(26.5-34.0)$ \\
Height $(\mathrm{cm})$ & $162(158.5-164.7)$ & $160(157.5-164.0)$ & $161(159.0-165.0)$ \\
Weight $(\mathrm{kg})$ & $76(69.2-83.5)$ & $72(65.5-79.7)$ & $74(69.5-78.7)$ \\
Gestational age (week) & $38(38-38)$ & $38(38-38)$ & $39(38-39)$ \\
Surgical duration (min) & $33(30.0-39.7)$ & $30(28.0-37.0)$ & $31(30.0-34.0)$ \\
\hline
\end{tabular}

IQR: interquartile range.

Table 2 Time Needed for Sensory Block (SB) to Reach $T_{10}, T_{6}$ and Motor Block (MB) Durations (Mean $\left.\pm S D\right)$.

\begin{tabular}{|c|c|c|c|}
\hline & $\begin{array}{l}\text { Group A } \\
(n=20)\end{array}$ & $\begin{array}{l}\text { Group AR } \\
(n=20)\end{array}$ & $\begin{array}{l}\text { Group R } \\
(\mathrm{n}=20)\end{array}$ \\
\hline Time for SB to reach $T_{10}(\min )$ & $\begin{array}{l}3.2 \\
(2.5-4) \dagger\end{array}$ & $\begin{array}{l}3.7 \\
(3-4.4) \neq\end{array}$ & $\begin{array}{l}5 \\
(5-7.1)\end{array}$ \\
\hline Time for SB to reach $\mathrm{T}_{6}(\mathrm{~min})$ & $\begin{array}{l}7.5 \\
(7.5-10) \dagger\end{array}$ & $\begin{array}{l}10 \\
(7.5-12.5) \ddagger\end{array}$ & $\begin{array}{l}15.5 \\
(12.5-20)\end{array}$ \\
\hline Time for SB to reach its maximum (min) & $\begin{array}{l}12.5 \\
(10-12.5) \dagger\end{array}$ & $\begin{array}{l}15 \\
(12.5-15) \neq\end{array}$ & $\begin{array}{l}20 \\
(20-28.7)\end{array}$ \\
\hline Maximum SB level & $\mathrm{T}_{5}$ & $\mathrm{~T}_{5}$ & $\mathrm{~T}_{4}$ \\
\hline Time for $S B$ to regress to $T_{6}(\min )$ & $\begin{array}{l}144 \\
(119-189)^{*} \dagger\end{array}$ & $\begin{array}{l}225 \\
(203-240) \neq\end{array}$ & $\begin{array}{l}281 \\
(252-318)\end{array}$ \\
\hline Two dermatome regression time, SB (min) & $\begin{array}{l}89 \\
(78-99)^{*} \dagger\end{array}$ & $\begin{array}{l}125 \\
(120-150) \neq\end{array}$ & $\begin{array}{l}156 \\
(130-184)\end{array}$ \\
\hline MB onset time (min) & $\begin{array}{l}12.5 \\
(7.5-15)\end{array}$ & $\begin{array}{l}12.5 \\
(10-14.4)\end{array}$ & $\begin{array}{l}12.5 \\
(12.5-15.0)\end{array}$ \\
\hline Total MB duration (min) & $\begin{array}{l}72.5 \\
(55-87.5)^{*} \dagger\end{array}$ & $\begin{array}{l}101.25 \\
(90-135.6) \ddagger\end{array}$ & $\begin{array}{l}192.5 \\
(162.5-245.0)\end{array}$ \\
\hline
\end{tabular}


Groups AR and R were similar (Table 3). When total ephedrine amounts were compared, the total amount in Group A was higher than in Group R ( $\mathrm{p}<0.05)$ (Table 3).

Minutes 1 and 5 Apgar scores of newborns were similar in all groups. None of the patients and surgeons reported poor satisfaction in the postoperative assessment, however Group A had a significantly lower satisfaction scores compared to Groups AR and R ( $<0.05)$.

\section{Postoperative analgesia and recovery}

The number of times patients pressing the button of the PCA device for their analgesic needs and the number of times the device administered medication to meet these needs were statistically higher in Group A than in Group R $(p<0.05)$ (Table 4). The time of first mobilization was shorter in Groups $A$ and AR than in Group R ( $p<0.05)$. The time of first gas passage was earlier in Group A than in Groups AR and $R$, and in Group AR than in Group R ( $<$ 0.05) (Table 4).

\section{Side effects}

The groups were not different in terms of side effect data observed $(p>0.05)$.

\section{Discussion}

The results of our study have demonstrated that administering epidural anesthesia with a combination of $0.75 \%$ ropivacaine and $2 \%$ articaine shortens onset of anesthesia in comparison with using $0.75 \%$ ropivacaine alone and provides longer anesthesia duration than $2 \%$ articaine. Motor and sensory block durations were significantly longer in the $0.75 \%$ ropivacaine group in comparison with $2 \%$ articaine and combination groups.

Articaine contains thiophene ring instead of benzene ring. This structural characteristic increases the lipid solubility of articaine and speeds its onset of action ${ }^{14,15}$. In addition, we know that the $\mathrm{pH}$ and $\mathrm{pKa}$ of local anesthetics affect their onset of action. Previous literature demonstrated that the pKa of ropivacaine was 8.05 and that of articaine was $7.8^{22}$. As the pKa of articaine is closer to tissue $\mathrm{pH}$, it may have contributed to the faster onset we observed. Previous studies of local anesthetic combinations for regional anesthesia combination groups have yielded favorable results in terms of onset and duration of anesthesia ${ }^{10,23-27}$. Magee et al. ${ }^{21}$ administered epidural anesthesia with bupivacaine alone or with bupivacaine-lidocaine mixture and found that combination group provides faster sensory block onset than bupivacaine

Table 3 Intraoperative Data of Administered Drugs (Mean \pm SD).

\begin{tabular}{|c|c|c|c|}
\hline & $\begin{array}{l}\text { Group A } \\
(n=20)\end{array}$ & $\begin{array}{l}\text { Group AR } \\
(n=20)\end{array}$ & $\begin{array}{l}\text { Group R } \\
(n=20)\end{array}$ \\
\hline $\begin{array}{l}\text { First ephedrine } \\
\text { time (min) }\end{array}$ & $8.4 \pm 2.7^{a}$ & $11.5 \pm 5.3$ & $13.3 \pm 5.5$ \\
\hline $\begin{array}{l}\text { Total ephedrine } \\
\text { (mg) }\end{array}$ & $\begin{array}{l}15.3 \pm 10.0^{a} \\
32.5 \pm 34.0^{b}\end{array}$ & $\begin{array}{l}10.25 \pm 9.2 \\
10.0 \pm 20.5\end{array}$ & $\begin{array}{l}9.0 \pm 7.1 \\
5.0 \pm 11.2\end{array}$ \\
\hline $\begin{array}{l}\text { Fentanyl }(\mu \mathrm{g}) \\
\text { Ketamine }(\mathrm{mg})\end{array}$ & $4.5 \pm 6.9^{b}$ & $0.50 \pm 2.2$ & 0.0 \\
\hline
\end{tabular}

alone, although their sensory block durations are similar. Cuvillon et al. ${ }^{24}$ compared bupivacaine and ropivacaine alone with equal volumes of bupivacaine-lidocaine and ropivacainelidocaine mixtures for femoral-sciatic nerve blockade. They also concluded that sensory block onset of action was faster in combination groups. Ye et al. ${ }^{25}$ administered a ropivacaine and lidocaine combination for caudal anesthesia and obtained faster onset of action and longer anesthesia duration in the combination group. Karahan et al. ${ }^{27}$ compared epidural anesthesia using a combination of $0.5 \%$ bupivacaine and $2 \%$ articaine with $0.5 \%$ bupivacaine and found that sensory block onset of action and duration was shorter in the combination group in comparison with bupivacaine group. Results of these studies are parallel to our results, which state that faster sensory block onset of action can be obtained by combining articaine and ropivacaine.

Morton et al. ${ }^{28}$ used $20 \mathrm{~mL} 0.75 \%$ ropivacaine for epidural anesthesia in cesarean operations and found that the first dose of local anesthetic provided the targeted $\mathrm{T}_{6}-\mathrm{S}_{3}$ sensory block level by $83 \%$, and the time needed to reach maximal sensory block level was 23 minutes. Bjqrnestad et al. ${ }^{29}$ administered epidural anesthesia with $20 \mathrm{~mL} 0.75 \%$ ropivacaine in elective cesarean operations, concluding that the maximum sensory block level was $T_{4}$ and the time needed to reach this level was 25 minutes. Both of these studies corroborate the results of our study concerning the maximal sensory block level and the time needed to reach this level in Group R.

Results of our study in terms of the time needed to reach maximum block was shorter in the articaine-ropivacaine group in comparison with ropivacaine group. This finding is parallel with previous studies of epidural anesthesia with articaine ${ }^{27,30}$.

We did not detect any difference between our groups regarding motor block onset times, and found that total motor block duration was shorter in the combination group than in the ropivacaine group. Parallel to our study, Kaukinen et al. ${ }^{31}$ found a significant decrease in motor block duration in their study, where they administered epidural anesthesia with a bupivacaine-lidocaine combination. On the other hand, our findings contradict those of Donner et al. ${ }^{32}$ which state that a combination of epidurally administered bupivacaine-prilocaine provides faster and more intensive motor block. We are also contradicted by Seow et al. ${ }^{26}$, in which a combination of bupivacaine-lidocaine provides more intensive motor block.

Table 4 Patient Demand and Bolus Numbers of PCA, Time to First Mobilization and Gas Removal According to the Groups [Median (min-max), (Mean \pm SD)].

\begin{tabular}{lcll}
\hline & $\begin{array}{c}\text { Group A } \\
(\mathrm{n}=20)\end{array}$ & $\begin{array}{l}\text { Group AR } \\
(\mathrm{n}=20)\end{array}$ & $\begin{array}{l}\text { Group R } \\
(\mathrm{n}=20)\end{array}$ \\
\hline Patient demand (n) & $16(9-36)^{\mathrm{a}}$ & $14(5-33)$ & $11(4-21)$ \\
$\begin{array}{l}\text { PCA bolus on } \\
\text { demand ( })\end{array}$ & $15(9-29)^{\text {a }}$ & $13(4-20)$ & $9(4-20)$ \\
$\begin{array}{l}\text { Time to first } \\
\text { mobilization (hr) }\end{array}$ & $9.8 \pm 2.4^{\text {a }}$ & $10.7 \pm 4.8$ a & $13.8 \pm 2.9$ \\
$\begin{array}{l}\text { Time to gas } \\
\text { removal (hr) }\end{array}$ & $20.8 \pm 5.1^{\text {b }}$ & $24.8 \pm 4.4$ a & $28.7 \pm 5.3$ \\
\hline $\begin{array}{l}\text { a: } \mathrm{p}<0.05 \text { (compared to Group R), b: } \mathrm{p}<0.05 \text { (compared to } \\
\text { Groups AR and R). }\end{array}$ & & &
\end{tabular}


In our study, motor block duration and level in the combination group was shorter and lower than the ropivacaine group, which we believe might have been caused by the fact that the differential block effect of ropivacaine emerges with greater strength in lower concentrations ${ }^{11-13,33}$.

Furthermore, the number of patients in the articaine group with VAS $\geq 3$ was higher. In line with this finding, the amount of intraoperatively consumed fentanyl and ketamine was higher in the articaine group than others (Table 3 ). In a study where they used $0.75 \%$ ropivacaine epidurally in cesarean operations, Bjqrnestad et al. ${ }^{29}$ and Irestedt et al. ${ }^{34}$ identified similar amounts of additional analgesic need, as was the case with our study's ropivacaine group.

With the neuroaxial blocks for cesarean section, hypotension is common. This is partially due to sympathetic block and tends to be treated with ephedrine, phenylephrine and crystalloid-colloid solution infusions ${ }^{2,3,35-37}$. In our study, onset of hypotension was earlier in the articaine group than in other groups; thus, the first ephedrine administration happened earlier than with other groups. This was due to more rapid sympathetic block effects obtained from the articaine group. We believe the higher MBP values from the articaine group to be the result of higher ephedrine consumption. The literature shows that epidural analgesia reduces postoperative pain and contributes to early mobilization, allowing earlier return of bowel functions, shortening hospitalization, and reducing costs ${ }^{38-40}$. In findings similar to our study, shorter first mobilization and gas removal times in the combination group is a result of shorter total motor and sensory block durations, which are favorable outcomes for cesarean section patients undergoing epidural anesthesia.

Studies of local anesthetic combinations aim to keep the benefits of the additive effects of the two local anesthetics, and avoid toxicity derived from the use of high volume primary medication for epidural and peripheral blocks ${ }^{21,41,42}$. Peak plasma concentrations of local anesthetics in the present study were not determined in this trial; thus, the safety of a ropivacaine-articaine combination in terms of high plasma local anesthetic concentrations remains to be determined. This would be an unexpected clinical scenario, however, considering the different pharmacokinetic profiles of these two drugs.

In conclusion, a combination of $0.75 \%$ ropivacaine with $2 \%$ articaine provides faster onset of action, earlier mobilization and gas removal time in comparison with $0.75 \%$ ropivacaine alone, as well as resulting in high patient and surgeon satisfaction rate. A $2 \%$ articaine- $0.75 \%$ ropivacaine combination for epidural anesthesia of cesarean section should be preferred over epidural $0.75 \%$ ropivacaine alone.

\section{References}

1. Carrie LES - Extradural, spinal or combined block for obstetric surgical anaesthesia. Br J Anaesth, 1990;65:225-233.

2. Dresner MR, Freeman JM - Anaesthesia for caesarean section. Best Pract Res Clin Obstet Gynaecol , 2001;15:127-143.

3. Gogarten W - Spinal anaestesia for obstetrics. Best Pract Res Clin Anaesthesiol, 2003;17:377-392.

4. Kallio H, Paloheimo M, Maunuksela EL - Hyaluronidase as an adjuvant in bupivacaine-lidocaine mixture for retrobulbar/ peribulbar block. Anesth Analg, 2000;91:934-937.
5. Axelsson K, Gupta A - Local anaesthetic adjuvants: neuraxial versus peripheral nerve block. Curr Opin Anaesthesiol, 2009;22:649-654.

6. Capogna G, Celleno D, Costantino P, Muratori F, Sebastiani M, Baldassini $M$ - Alkalinization improves the quality of lidocainefentanyl epidural anaesthesia for caesarean section. Can J Anaesth, 1993;40:425-430.

7. Vercauteren $M$ - Obstetric spinal analgesia and anesthesia. Curr Opin Anaesthesiol, 2003;16:503-507.

8. Liepert DJ, Douglas MJ, McMorland GH, Gambling DR, Kim JH, Ross PL - Comparison of lidocaine CO2, two per cent lidocaine hydrochloride and $\mathrm{pH}$ adjusted lidocaine hydrochloride for caesarean section anesthesia. Can J Anaesth, 1990;37:333336.

9. Goring-Morris J, Russell IF - Randomised comparison of $0.5 \%$ bupivacaine with a lidocaine/ epinephrine/ fentanyl mixture for epidural top-up for emergency caesarean section after "low dose" epidural for labour. Int J Obstet Anesth, 2006;15:109114.

10. Howell P, Davies W, Wrigley M, Tan P, Morgan B - Comparison of four local extradural anaesthetic solutions for elective caesarean section. Br J Anaesth, 1990;65:648-653.

11. Akerman B, Hellberg IB, Trossvik C - Primary evaluation of the local anaesthetic properties of the amino amide agent ropivacaine. Acta Anaesthesiol Scand, 1988;32:571-578.

12. Marsh CR, Hardy PAJ - Ropivacaine: a new local anaesthetic agent. Br J Hosp Med, 1991;45:94-95.

13. Stienstra $R$ - The place of ropivacaine in anesthesia. Acta Anaesthesiol Belg, 2003;54:141-148.

14. Malamed SF, Gagnon S, Leblanc D - Articaine hydrochloride: a study of the safety of a new amid local anesthetic. JADA, 2001;132:177-185.

15. Oertel R, Rahn R, Kirch W - Clinical pharmacokinetics of articaine. Clin Pharmacokinet, 1997;33:417-425.

16. Kallio H, Snäll E-VT, Luode T, Rosenberg PH - Hyperbaric articaine for day-case spinal anaesthesia. Br J Anaesth, 2006;97:704709.

17. Vree TB, van Oss GE, Gielen MJ, Booij LH - Epidural metabolism of articaine to its metabolite articainic acid in five patients after epidural administration of $600 \mathrm{mg}$ articaine. J Pharm Pharmacol, 1997;49:158-163.

18. Vree TB, Simon MA, Gielen M J, Booij LH - Regional metabolism of articaine in 10 patients undergoing intravenous regional anaesthesia during day case surgery. $\mathrm{Br} \mathrm{J}$ Clin Pharmacol, 1997;44:29-34.

19. Culea M, Palibroda N, Moldovan Z, Abraham AD, Frangopol PT - Gas chromatographic study of some local anesthetics. Chromatographia, 1989;28:24-26.

20. Arslan G, Karamanlıoğlu B, Pamukçu Z - Epidural anestezide \% 2 kartikain ve \% 0.5 bupivakain. Türk Anest Rean Cem Mecmuası, 1999;27:355-360.

21. DSS Research. Calculator. Available at: http://www.dssresearch. com/KnowledgeCenter/toolkitcalculators/samplesizecalculators. aspx.

22. Graf BM, Niesel HC - Pharmakologie der Lokalnaesthetika. Lokalnaesthesie, Regionalanaesthesie, Regionale Schmerztherapie.2. überarbeitete Aufgabe. Niesel HC, Aken HV (eds) G.Thieme Verlag, Stuttgart, 2003, pp. 60.

23. Magee DA, Sweet PT, Holland AJC - Epidural anaesthesia with mixtures of bupivacaine and lidocaine. Can Anaesth Soc J, 1983;30:174-178.

24. Cuvillon P, Nouvellon E, Ripart J et al. - A comparison of the pharmacodynamics and pharmacokinetics of bupivacaine, ropivacaine (with epinephrine) and their equal volume mixtures with lidocaine used for femoral and sciatic nerve blocks: a double-blind randomized study. Anesth Analg, 2009;108:641649. 
25. Ye F, Feng YX, Lin JJ - A ropivacaine-lidocaine combination for caudal blockade in haemorrhoidectomy. J Int Med Res, 2007;35:307-313.

26. Seow LT, Lips FJ, Cousins MJ, Mather LE - Lidocaine and bupivacaine mixtures for epidural blockade. Anesthesiology, 1982;56:177-183.

27. Karahan E, Eroğlu F, Ceylan BG, Uçar A, Ergin Ç - Epidural anestezide bupivakaine artikain ilavesi duyusal blok bașlangıcını hızlandırmaktadır. Türk Anest Rean Der Dergisi, 2004;32:193-199.

28. Morton CP, Bloomfield S, Magnusson A, Jozwiak H, McClure $\mathrm{H}$ - Ropivacaine $0.75 \%$ for extradural anaesthesia in elective caesarean section: an open clinical and pharmacokinetic study in mother and neonate. Br J Anaesth, 1997;79:3-8.

29. Bjqrnestad E, Smedvig JP, Bjerkreim T, Narverud G, Kollerqs D, Bergheim R - Epidural ropivacaine $7.5 \mathrm{mg} / \mathrm{ml}$ for elective Caesarean section: a double-blind comparison of efficacy and tolerability with bupivacaine $5 \mathrm{mg} / \mathrm{ml}$. Acta Anaesthesiol Scand, 1999;43:603-608.

30. Kaukinen L, Kaukinen S, Karkkainen S - Epidural anaesthesia with carticaine in cesarean section. A comparison with bupivacaine. Anaesthesist-Reg Anaesth, 1986;9:79-83.

31. Kaukinen S, Kaukinen L, Eerola R - Epidural anaesthesia with mixtures of bupivacaine-lidocaine and etidocaine-lidocaine. Ann Chir Gynaecol, 1980;69:281-286.

32. Donner B, Tryba M, Sokolew J, Strumpf M - Does the mixture of bupivacaine and prilocaine as opposed to bupivacaine afford a clinical advantage in epidural anesthesia? Anaesthesist, 1993;42:295-299.

33. Keeffe NJO, Healy TEJ - The role of new local agents. Pharm Ther, 1999;84:233-248.
34. Irestedt L, Emanuelsson BM, Ekblom A, Olofsson C, Reventlid $\mathrm{H}$ - Ropivacaine $7.5 \mathrm{mg} / \mathrm{ml}$ for elective Caesarean section. A clinical and pharmacokinetic comparison of $150 \mathrm{mg}$ and 187.5 mg. Acta Anaesthesiol Scand, 1997;41:1149-1156.

35. Chestnut DH - Anesthesia and maternal mortality. Anesthesiology, 1997;86:273-276.

36. McKinlay J, Lyons G - Obstetric neuraxial anaesthesia: which pressor agents should we be using? Int J Obst Anaesth, 2002;11:117-121.

37. Lee A, Kee WDN, Gin T - A quantitative, systematic review of randomized controlled trials of ephedrine versus phenylephrine for the management of hypotension during spinal anesthesia for Cesarean delivery. Anesth Analg, 2002;94:920-926.

38. Jorgensen H, Fomsgaard JS, Dirks J, Wetterslev J, Andreasson B, Dahl JB - Effect of peri- and postoperative epidural anaesthesia on pain and gastrointestinal function after abdominal hysterectomy. Br J Anaesth, 2001;87:577-583.

39. Stevens RA, Mikat-Stevens M, Flanigan R et al. - Does the choice of anesthetic technique affect the recovery of bowel function after radical prostatectomy? Urology, 1998;52:213-218.

40. Wattwil M, Thoren T, Hennerdal S, Garvill JE - Epidural analgesia with bupivacaine reduces postoperative paralytic ileus after hysterectomy. Anesth Analg, 1989;68:353-358.

41. De Jong R, Bonin J - Mixtures of local anesthetics are no more toxic than the parent drugs. Anesthesiology, 1981;54:177181.

42. Moore DC, Bridenbaugh LD, Bridenbaugh PO, Thomson GE, Tucker GT - Does compounding of local anesthetic agents increase their toxicity humans? Anesth Analg, 1972;51:579-585. 